\title{
Sickle cell disease
}

Studying arteries with Doppler ultrasound

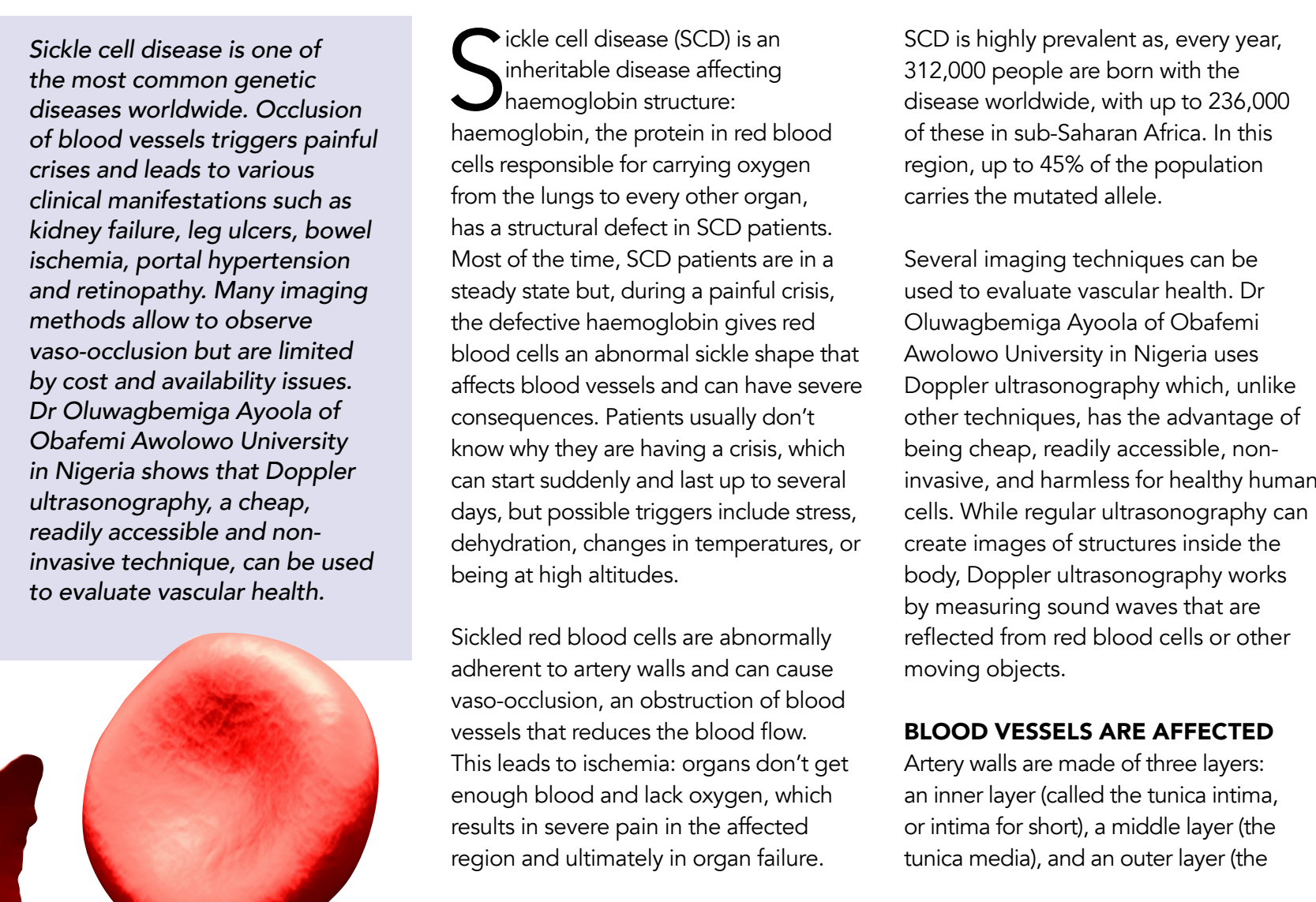

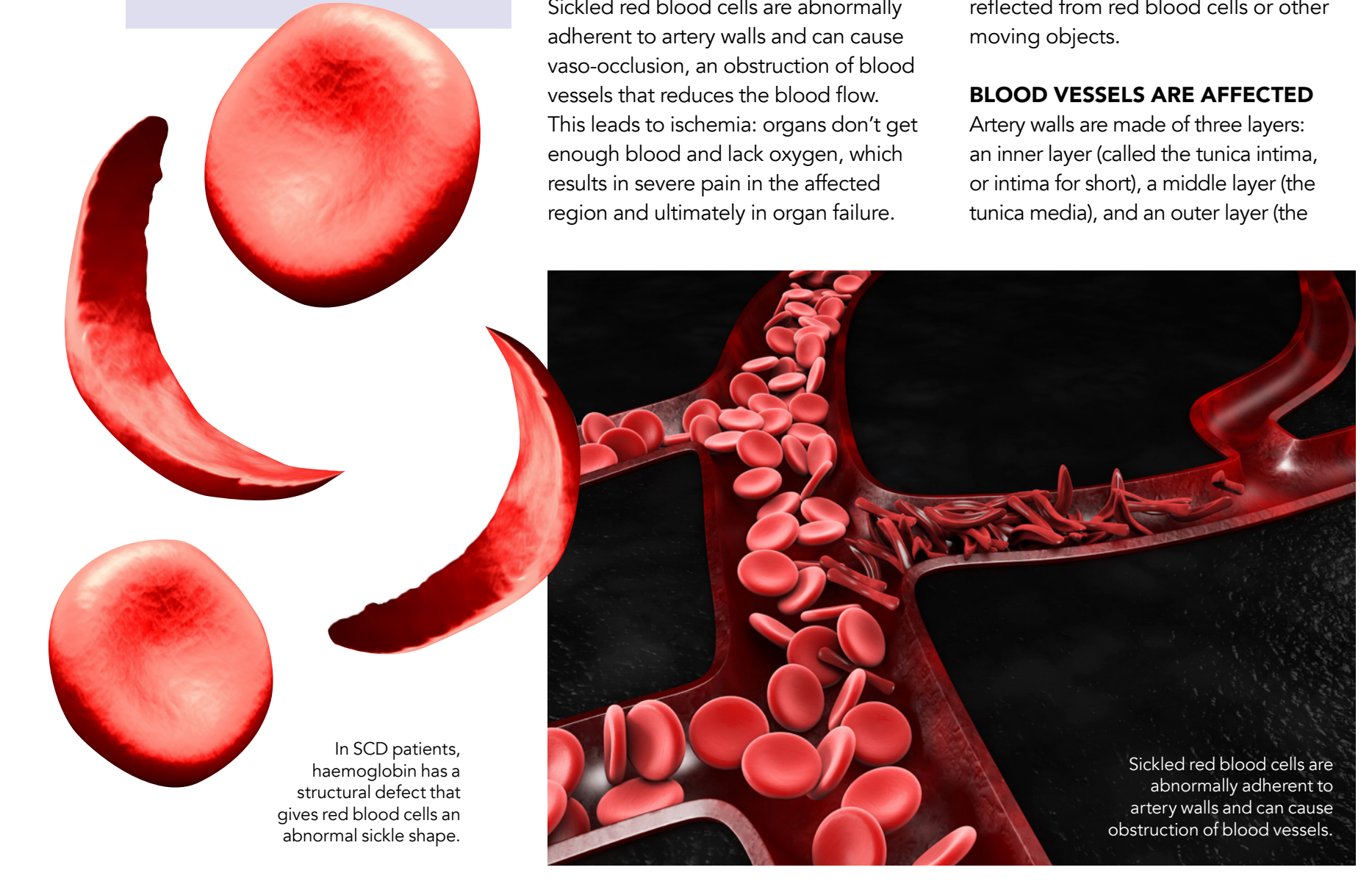

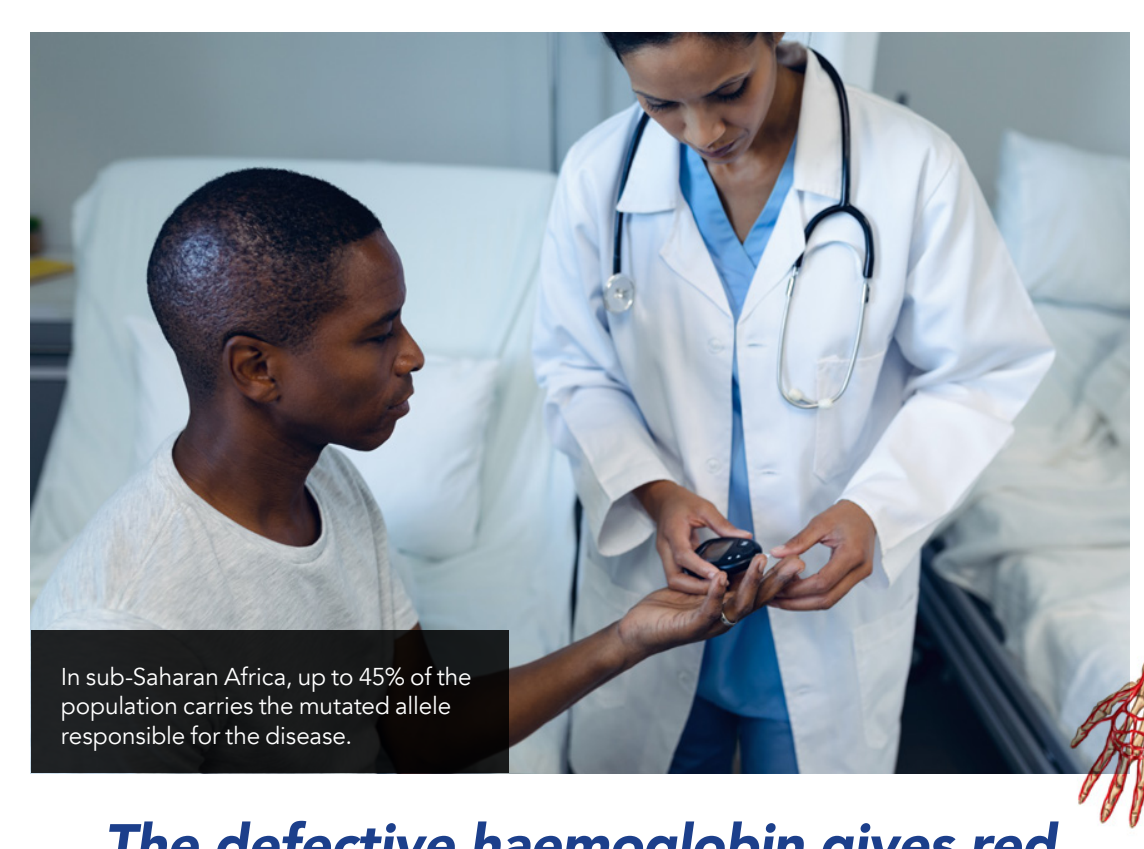

The defective haemoglobin gives red blood cells an abnormal sickle shape that affects blood vessels and can have severe consequences. endothelium (a thin layer of cells) that is in blood flow to compensate for low oxygen direct contact with the blood flow. levels. This physiological mechanism is

In SCD patients, sickled red blood orchestrated by the vascular endothelium. cells adhere excessively to the vascular impaired; measuring FMD allows to reveal endothelium, which results in occlusion endothelial dysfunction. In SCD patients, in small vessels and in intima-media thickening in arteries, meaning that the artery wall thickens. This affects the blood flow and causes a lack of oxygen which damages the endothelium. The damaged endothellum is unable to thetion propely - this is called endothelial dystunction. by the impaired blood flow further affects the blood flow. This vicious cycle is the origin of various complications in the surrounding tissues and organs.

TOOLS TO ASSESS VASCULAR HEALTH Dr Ayoola and his co-researchers use Doppler ultrasonography in different arteries to assess vascular health through different measures. Intima-media thickness (IMT) is a useful measure of the thickness of artery walls. Intina-media thickening due to sickledred blood cells directy mpacts this measure: in SCD patients, IMT is greater.

Measuring flow-mediated dilation (FMD) consists in measuring the ability of the FMD is therefore reduced.

Doppler ultrasonography can also be used to measure parameters such as speed of moving blood within the arteries and resistance to blood flow. Through al these measures, ultrasonography allows

\section{ENDOTHELIAL DYSFUNCTION} AND RENAL IMPAIRMENT The kidney is one of the organs that can be damaged in SCD: by measuring FMD and resistance to blood flow in the renal artery in SCD patients, Dr Ayoola and his
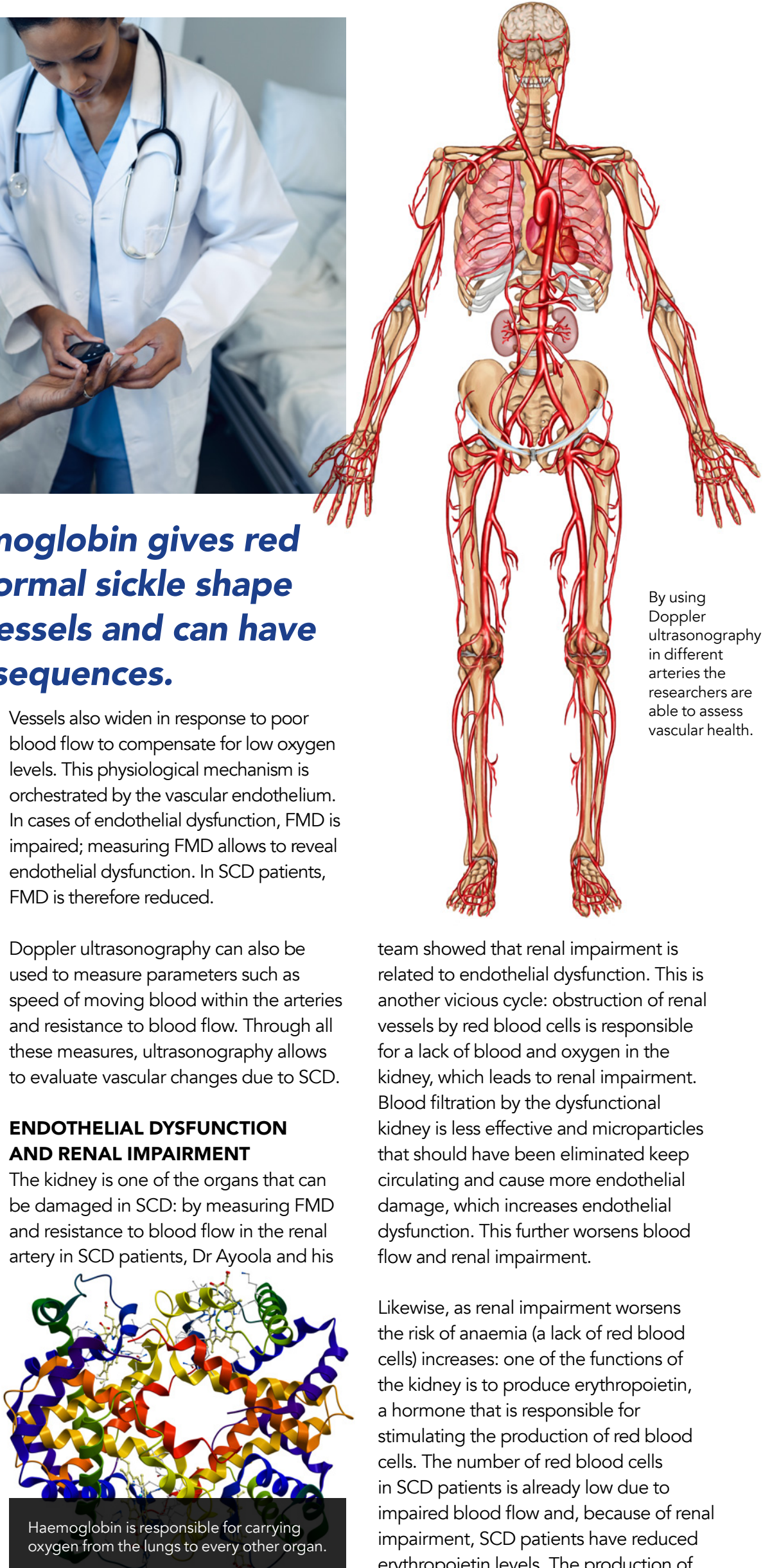

team showed that renal impairment is related to endothelial dysfunction. This is

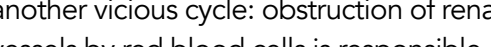
vessels by red blood cells is responsible for a lack of blood and oxygen in the Blood filtration by the dysunctiona kidney is less effective and microparticles that should have been eliminated keep circulating and cause more endothelial damage, which increases endothelial dysfunction. This further worsens blood flow and renal impairment.

Likewise, as renal impairment worsens the risk of anaemia (a lack of red blood cells) increases: one of the functions of the kidney is to produce erythropoietin a hormone that is responsible for stimulating the production of red blood cells. The number of red blood cells in SCD patients is aleady low due to impaired blood flow and, because of ren impairment, SCD patients have reduced 


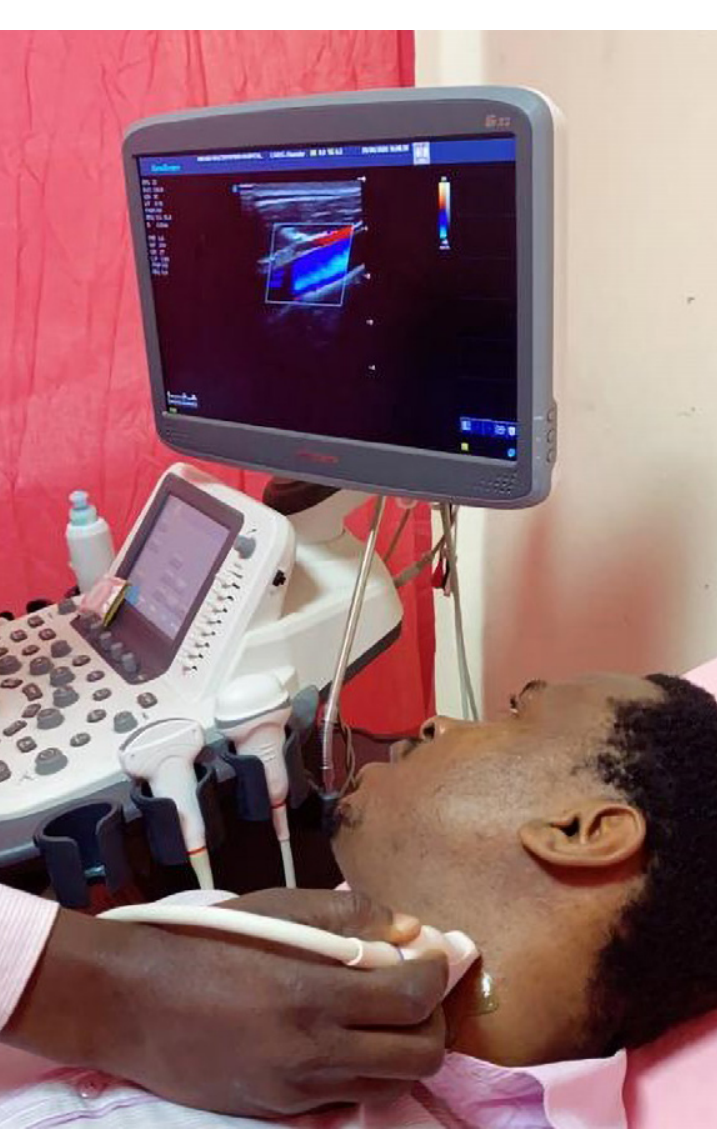

Dopple ultrasonography measures sound
waves that are reflected from red blood cells or other moving objects in
structures inside our body.

ed blood cells is not stimulated, which further reduces the number of red blood cells and increases the risk of

CHRONIC LEG ULCERATION athological vascular changes occurring in SCD are also the origin of leg ulceration, a ore Using Doppler utrasound to measur IMT of the common femoral artery, a major artery in the leg, Dr Ayoola and his team found that chronic leg ulceration, a possible complication of SCD, is associated with intima-media thickening the artery wall of the common femoral artery is thicker in SCD patients with history of leg ulceration than in SCD patients without such history, which suggests that pathological vascular changes play a major role in the formation of these ulcers.

BOWEL ISCHEMIA

The celiac and mesenteric arteries nourish the digestive system. Abdominal pain

is a symptom of bowel ischemia, which by sickled red bese arteries are obstructed
Bowel ischemia is uncommon, but it is associated with significant mortality.

The research group used Doppler

ultrasound to evaluate the celiac and

abnormal narrowing of the arteries that

can result in severe visual impairment.

The group measured the speed of

The ability to predict the severity of the disease from measures of vascular changes could contribute to better management of the patients.

could be related to bowel ischemia. While moving blood within the central retinal tw was known that bowel ischemia could vessels, he showed that vascular change vessels, he showed that vascullar hanges

\section{LIVER DYSFUNCTION AND} PORTAL HYPERTENSION

The liver is an organ whose cells, the

hepatocytes, carry out various functions mostly involved in digestion. When sickled red blood cells affect hepatic sinusoids (microscopic vessels within the liver), the lack of oxygen due to the reduction of blood flow injures the hepatocytes. This results in liver dystunction, and, more precisely, in a condition called sickle cell intrahepatic chestive fluid, a By observing hepatic veins with Doppler ultrasound, Dr Ayoola and his team found hat, in addition to causing liver ultimately lead to porta hypertension, an increase in the blood pressure in the portal vein which carries the blood from the bowel to the liver: because blood flow through the liver is impaired, blood cannot enter the liver and mounts up in the portal vein.

carotid IMT. The carotid IMT is higher is SCD patients and correlates with the speed of moving This suggests that the cartidal artery. be used as a marker of ocular changes: mesuring the carotid IMT can be sufficient for estimating changes in the central retinal artery.

TOWARDS A MORE EFFECTIVE PREVENTION Working in a developing country where access to some imaging techniques is limited by cost and availability issues, Dr Ayoola shows that Doppler ultrasonography can be an effective too to evaluate vascular health and to make connections between vascular changes pourring in different arteries and various possible complications.

His research is part of an ongoing quest to lis to predict the severity of the disease from measures of vascular changes could lead to more effective prevention and may help clinicians to prevent the severe complications that may arise from occlusion of the arteries.

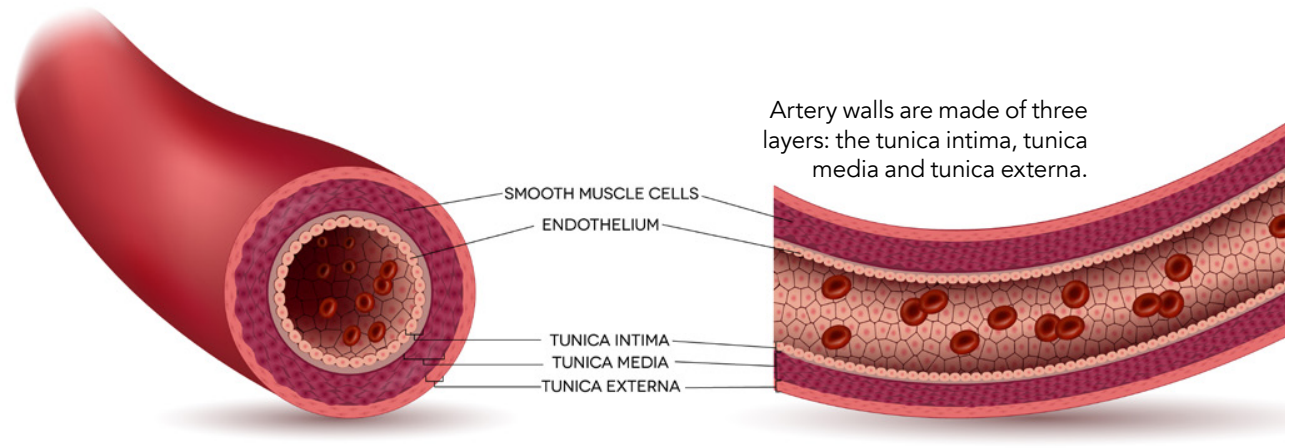

\section{Behind the Research}

Dr Oluwagbemiga Ayoola

E: oluwagbemiga.ayoola@npmcn.edu.ng T: +2348034754040

W: www.researchgate.net/profile/Oluwagbemiga_Ayoola

\section{Research Objectives}

Oluwagbemiga Ayoola uses Doppler ultrasound to study arterial occlusion in patients with sickle cell disease.

\section{Detail}

Oluwagbemiga Ayoola

Faculty of Clinical Sciences

Obafemi Awolowo University

Osun State 230001

Nigeria

Bio

Oluwagbemiga Ayoola is currently a Senior lecturer and the Acting Head of the Radiology Department at the Obafemi Awolowo University, lle-lfe, Nigeria. His researc focus, over the last few years, has been on vascular maging especially in sickle cell disease.

Funding

bafemi Awolowo University Teaching Hospital, lle-lfe, Osun State, Nigeria

Collaborators

Rahman A. Bolarinwa

- Oluwatoyin H. Onakpoya

- Tewogbade A. Adedeji

- Chidiogo C. Onwuka

- Adeniyi S. Aderibigbe
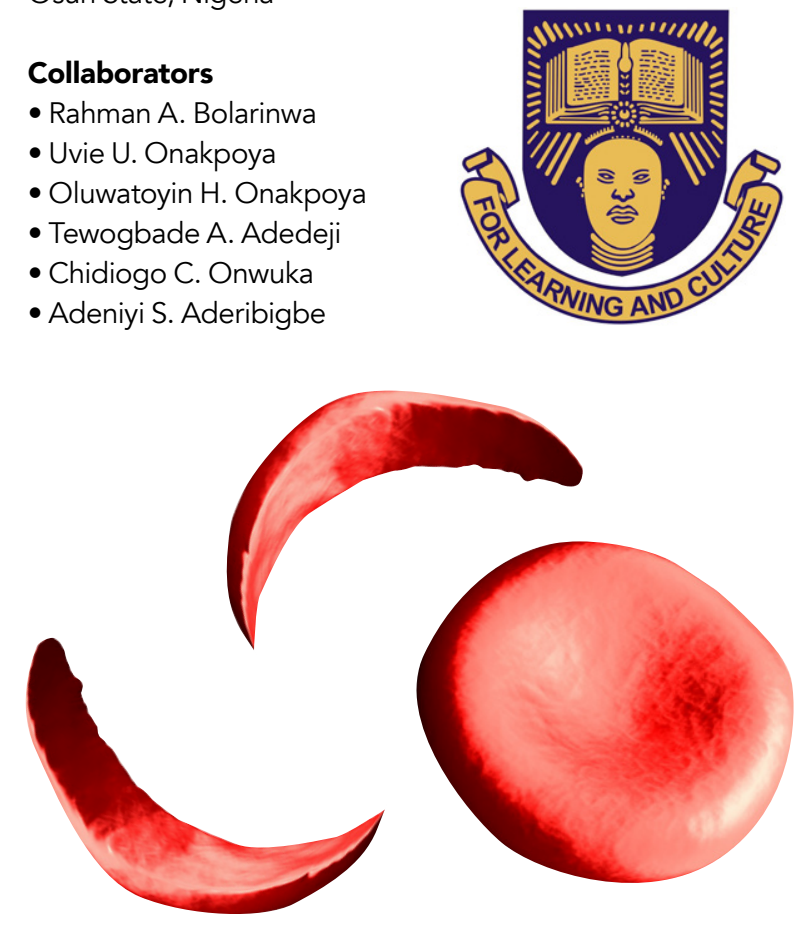

References

Ayoola, O.O., Bolarinwa, R.A., Aderibigbe, A.S., Onigbinde, S.O., and Oguntade, B. O. (2020). Portal hypertension evolving from sickled hepatopathy: could hepatic venous Doppler ultrasound be beneficia in its evaluation? Medical hypotheses, [online] 135. Available at: https://doi.org/10.1016/ mehy.2019.109450

Ayoola, O.O., Bolarinwa, R.A., Onakpoya, O.H., Onigbinde, S.O., Asaleye, C.M., and Odedeyi, A.A. (2020). Intimamedia thickness of the common carotid arteries as a marker of retinopathy and nephropathy in sickle cell disease. Ultrasonography (Seoul, Korea), 39(1), 79-84. Available at: https://doi.org/10.14366/usg.19016

Ayoola, O.O., Bolarinwa, R.A., Onwuka, C.C., Idowu, B.M., and Aderibigbe, A.S. (2020). Association between Endothelia Dysfunction, Biomarkers of Renal Function, and Disease Severity in Sickle Cell Disease. Kidney360, 1(2), 79-85.
Available at: https://doi.org/10.34067/KID.0000142019

Ayoola, O.O., Bolarinwa, R.A., Onakpoya, U.U., Onwuka, C.C., Adedeji, T.A., Afolabi, B. I., Onigbinde, S.O., and Arogundade, F.A. (2019). Doppler ultrasonographic evaluation of celiac and mesenteric arteries in subjects with sickle Avilable at: Lttps//doiorg/101002/j/ 22729

Ayoola, O.O., Bolarinwa, R.A., Onakpoya, U.U., Adedeji, T.A., Onwuka, C.C., and Idowu, B.M. (2018). Intima-media thickness of the common femoral artery as a marker of leg 2(22), 3112-3117. Available at: https:///doi.org/10.1182/ bloodadvances.2018023267

\section{Personal Response}

How are you planning to advance your research? II I would like to further confirm some of my findings especially in relation to bowel ischemia where intend angiographic studies on the coeliac and mesenteric arteries and also biochemically ascertain the possibility of these subjects having portal hypertension. We are also conside studying the coronary arteries by carrying out computed
tomographic angiographic studies of these arteries. 